\title{
Tracer imaging in lung cancer
}

\author{
Hussein M. Abdel-Dayem¹, Andrew Scott², Homer Macapinlac², Steven Larson² \\ 1 Department of Radiology, Nuclear Medicine Service, St. Vincent's Hospital and Medical Center of New York, \\ 153 W 11th Street, New York, NY 10011, USA \\ 2 Department of Radiology, Memorial Sloan-Kettering Cancer Center
}

\section{Eur J Nucl Med (1994) 21:57-81}

In the above review article, the results and evaluation of 19 studies in references $171-189$ cited in the "Monoclonal antibodies" section were quoted from a review article published earlier by another team of authors: "Imaging lung cancer with radiolabeled antibodies" by Hazel B. Breitz, Kathleen Sullivan and Wil B. Nelp in Semin Nucl Med 22: 127-132, April 1993. In the section on imaging perfusion and hypoxia in the second paragraph, Groshar et al. (reference 209) were mistakenly cited with reference to experience with 18F-fluoromisonazole imaging (FMISO). The correct reference should have been Koh WJ, Rasay JS, Evans ML, Casciari JJ and Graham MM,' Imaging of hypoxia and reoxygenation in human tumors with [F-18] Fluoromisonazole [Abstract] J Nucl Med 1993; 34: 21P (reference 211 in the same review). The principal author of this review article apologizes to both Dr. Breitz and
Dr. Koh. The verbatim transcription of the results of the 19 studies in Dr. Breitz's review article or Dr. Koh's abstract was not an attempt to downplay their achievements, and the results should have been enclosed in quotation marks. The leadership of Dr. Breitz in the field of monoclonal antibodies and of Dr. Koh in the area of imaging tumor hypoxia is well recognized. The review article by Dr. Breitz is highly recommended for all those interested in the devlopments of monoclonal antibodies imaging of lung cancer.

Hussein Abdel-Dayem, M.D.

Professor of Radiology

Chief, Nuclear Medicine Service

St.-Vincent's Hospital and Medical Center of New York. 